\title{
Simulated SAM A-scans on multilayer MEMS components
}

\author{
Janting, Jakob; Petersen, Dirch Hjorth; Greisen, Christoffer
}

Published in:

Proceedings of Workshop on MEMS Sensor Packaging.

Publication date:

2003

Document Version

Publisher's PDF, also known as Version of record

Link back to DTU Orbit

Citation (APA):

Janting, J., Petersen, D. H., \& Greisen, C. (2003). Simulated SAM A-scans on multilayer MEMS components. In Proceedings of Workshop on MEMS Sensor Packaging.

\section{General rights}

Copyright and moral rights for the publications made accessible in the public portal are retained by the authors and/or other copyright owners and it is a condition of accessing publications that users recognise and abide by the legal requirements associated with these rights.

- Users may download and print one copy of any publication from the public portal for the purpose of private study or research.

- You may not further distribute the material or use it for any profit-making activity or commercial gain

- You may freely distribute the URL identifying the publication in the public portal

If you believe that this document breaches copyright please contact us providing details, and we will remove access to the work immediately and investigate your claim. 


\title{
Simulated SAM A-scans on multilayer MEMS components
}

\author{
Jakob Janting ${ }^{\mathrm{a}}$, Dirch Hjorth Petersen ${ }^{\mathrm{b}}$, Christoffer Greisen ${ }^{\mathrm{c}}$ \\ ${ }^{a}$ DELTA Danish Electronics, Light \& Acoustics, Venlighedsvej 4, DK-2970 Hoersholm, Denmark \\ e-mail: jaj@delta.dk, Fax:+45 721940 01,URL: http://www.delta.dk \\ ${ }^{b}$ MIC, Building 345, DK-2800 Lyngby, Denmark \\ ${ }^{c}$ Danfoss A/S, CAT/DTU, Building 347, DK-2800 Lyngby, Denmark
}

\section{Introduction}

SAM has been used for several years as a microelectronics failure analysis tool though often with poor understanding of the A-scan and C-scan pictures. This is especially the case when the components consist of layers very close to each other and where phase inversions take place.

Most often MEMS contain stacks of many very thin layers. The motivation for this work has therefore been to gain better understanding of SAM A-scans on MEMS multilayer structures by simulation.

\section{Results}

All calculations have been made in an excel spreadsheet. SAM measurements were made on KSI Winsam 200 equipment.

\subsection{Spreadsheet calculations}

For given sets of reflections we calculate for each first the number $N$ of possible reflection orders. The calculations are based on maximum 4 or 9 impedance transitions with up to 8 or 2 reflections back towards the transducer respectively (Fig. 1). Then the received amplitudes with polarity according to (1) together with the corresponding delay times are calculated.

$$
A=A_{0} \cdot N \cdot T_{\text {total }} \cdot R_{\text {total }}
$$

$T_{\text {total }}$ and $R_{\text {total }}$ are the products of all involved transmission and reflection coefficients. Due to limited available data the sound attenuation in each layer is not yet included in the calculations, however, the program is prepared for this. The spreadsheet input values are the materials acoustic impedances, the speed of sound in the materials, and the layer thicknesses.

\subsection{A-scans on fusion bonded wafers}

Bonded silicon wafers with test cavities for an absolute pressure sensor have been investigated with SAM. The cavities are used to test the leakage through the bond interface into the cavity [1]. Over the cavities and down the layers are $\mathrm{Si}(350 \mu \mathrm{m}) /$ cavity $(2 \mu \mathrm{m}) / \mathrm{Si}(500 \mu \mathrm{m}) / \mathrm{SiN}$ $(0.1 \mu \mathrm{m})$.

Simulations show that in order to get a scan of the interface with a minimum of overlapping waves out of phase the bonded wafers should be inspected from the Si side (Fig. 2). Then all the reflected waves have the same sign and

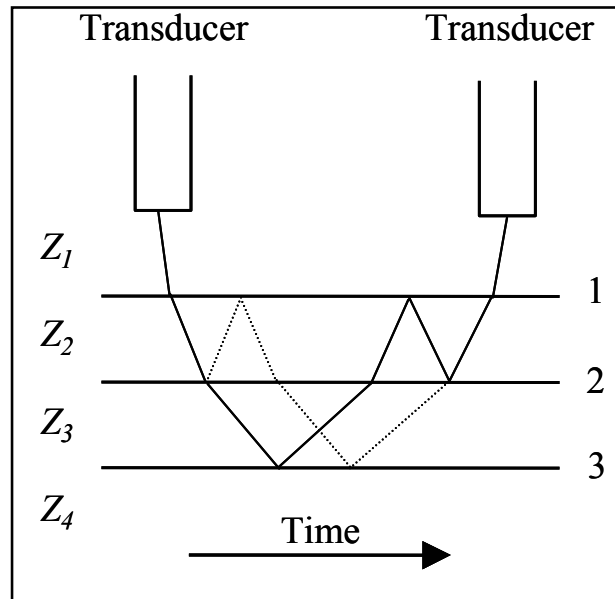

Fig. 1. Illustration of two waves which are equal because they are reflected at the same interfaces only in different order (3-1-2, 2-1-3). They are therefore received at the transducer at the same time. are well separated because the time between them is $83 \mathrm{~ns}$. Though, by comparing the real scan from the Si side (Fig. 3) with the simulations it is evident that this looks more like the one expected when scanning from the SiN side (Figs. 2 and 3).

\section{Discussion}

Spectra much like the one from the SiN side are achieved no matter the thin layer material and position at the exterior or next to the cavities and channels. Therefore we suggest that the thin boron diffused bond layer is acoustically different from bulk silicon, which was not expected from the start. This is supported by 
the observation that stresses built-up in such layers, which might change the longitudinal acoustic impedance of silicon significantly. I.e. we have the layers: $\mathrm{Si}(350 \mu \mathrm{m}) /$ approx. $2 \mu \mathrm{m}$ B diffused Si / cavity $(2 \mu \mathrm{m}) / \mathrm{Si}(500 \mu \mathrm{m}) / \mathrm{SiN}(0.1$ $\mu \mathrm{m})$.

Apart from the time position differences due to differences in Si thickness before the cavity, the real scan from the $\mathrm{Si}$ side resembles the A-scan simulation of inspection from the SiN side quite well because waves of opposite amplitude sign seem to overlap more or less. Note that only two signals from the interface are clearly seen, i.e. the first and second time reflections from cavities / channels at around $83 \mathrm{~ns}, 166 \mathrm{~ns}$ and $118 \mathrm{~ns}, 237 \mathrm{~ns}$ in the real scan from the Si side (Figs. 2 and 3) and in the simulation of inspection from the SiN side (Fig. 2) respectively. The rest of the signals essentially die because waves with opposite phase are added. Already from the second time echoes this begins to happen e.g. by addition of 3-1-3-.. and 3-2-3-.. reflections in the case of inspection from the SiN side. Even though the second time reflection from the cavity has passed two times through the silicon material, the amplitude is high because of the high $N$ value.

\section{Conclusion}

A calculation method and spreadsheet program for simulation of SAM A-scans on multilayer structures have been developed. The useful information, which the simulations provide, has been demonstrated on fusion bonded wafers containing MEMS pressure sensor test cavities in the interface. Unexpectedly it was found that an extra layer on the wafer without etched cavities / channels has influence on the A-scans. Presumably this layer is a B diffused bond layer.

Generally, it has been shown that structure variations in samples can be simulated and therefore analysed better. Failures or variations in MEMS structures can be analysed by investigating the effect of introducing them in the A-scan simulations and comparing them with real A-scans.

\section{Acknowledgement}

This work has been part of the collaboration on development of microsystems (SUM) project between two Danish institutes DELTA, the Microelectronics Centre (MIC), and four Danish companies Capres A/S, SonionMEMS A/S, Danfoss A/S and Grundfos A/S. The project is financially supported by the Danish Agency for Trade and Industry.
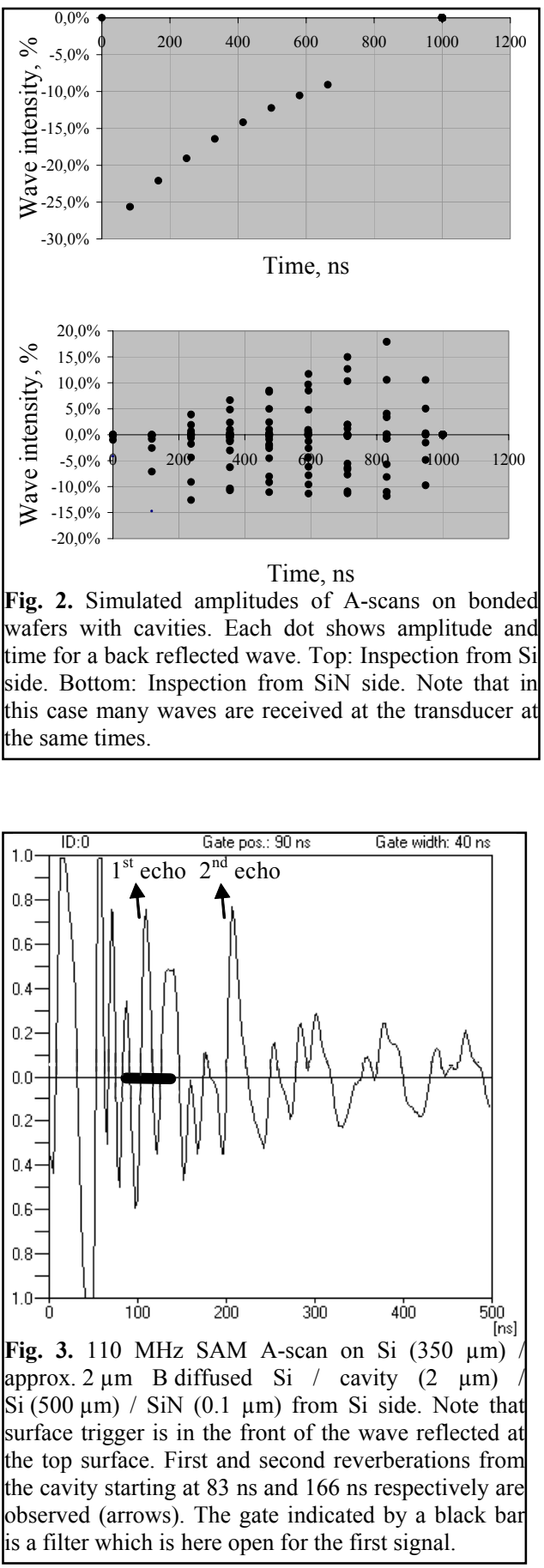

\section{References}

[1] K. Birkelund, M. Sørensen, S. Chiriaev, P. Gravesen and P. B. Rasmussen, High pressure sensor based on fusion bonding, abstract 1482 in: Proc. of the $6^{\text {th }}$. Int. Symp. on Semiconductor Wafer Bonding: Science, Technology and Applications, The Electrochem. Soc., San Francisco (2001). 